\title{
Revista Médica Herediana: Once años después.
}

Hace once años atrás en 1990, se dio origen a la Revista Médica Herediana. Desde su nacimiento los editores de la revista consideraron que debía ser autofinanciada y distribuida por suscripción, a diferencia de otras revistas del medio. Es así, que para la publicación del primer número contribuyeron 40 profesores en calidad de socios de honor, quienes a cambio de su contribución recibirían una suscripción de por vida de la nueva revista.

Entre los meses de junio y octubre de 1990, los profesores editores dedicaron tiempo valioso en la captación de los socios de honor, la elaboración del reglamento de la revista, la recepción de investigaciones originales y de temas de revisión y en la búsqueda de donaciones. El resultado fue la aprobación de la Revista Médica Herediana como Organo Oficial de la Facultad de Medicina Alberto Hurtado primero por el Consejo de la Facultad de Medicina y luego por el Consejo Universitario y la edición del primer número de la revista, cuya presentación oficial fue en noviembre del mismo año.

Es necesario hacer un reconocimiento a las empresas que nos apoyaron en la edición de los primeros números, algunas de ellas sin relación con el área médica o farmacéutica quienes nos brindaron su apoyo económico y con donación de papel.

El Dr. Roger Guerra-García, rector de la Universidad en la editorial del primer número señaló: "Numerosas son las revistas médicas publicadas en el Perú, la mayoría fueron de vida fugaz, unas pocas tuvieron calidad y continuidad, esta Revista Médica Herediana aspira a reunir ambas virtudes." (1)

Tener calidad y continuidad han sido los objetivos de nuestra revista durante estos años; para ello desde 1994 se implementó el arbitraje editorial con la participación voluntaria de muchos profesores de nuestra Facultad, con ello estoy seguro que la calidad de los estudios originales de investigación publicadas en la revista ha ido y continúa mejorando. Además, los editores han participado como expositores en numerosos cursos de metodología de investigación y otros eventos científicos aportando sobre aspectos relacionados a la publicación científica y el sesgo de publicación.

Como otro objetivo de las revistas científicas es la educación continua, la revista médica herediana ha publicado temas de revisión, de salud pública, de historia, de reflexión, etc, que de alguna manera han contribuido al conocimiento de nuestros lectores en temas poco conocidos.

La revista ha cumplido con la continuidad, sin embargo no se ha podido cumplir con la temporalidad, debido a múltiples factores entre ellos la situación económica del país y la reducida recepción de artículos de investigación original. Pero, aún faltan tareas por realizar, entre las que se incluye la evaluación del impacto de la revista en los investigadores y lectores.

En la actualidad, en la era de la globalización, en la que la información debe ser de acceso universal, ¿Qué papel y 
objetivos tendrá la revista médica herediana?. El papel, no debe cambiar, seguirá siendo: la difusión de los resultados de investigación, la educación médica continua y reducir o evitar el sesgo de publicación (2); sin embargo, la forma como lo realice deberá ser acorde a los avances de la tecnología de la información. Por lo tanto, se deberá publicar una versión digitalizada y tener acceso vía internet.

Hacia esa dirección trabaja la revista, en la actualidad se encuentra en la base de datos Lilacs en forma de resúmenes y pronto tendrá acceso por internet en formato texto.

Creo, sin embargo que el éxito que pueda tener la revista en el futuro no depende exclusivamente de los editores ni de la institución, requiere además de la contribución de los investigadores, de los revisores (arbitraje editorial) y de los lectores.

* Dr. Juan Miyahira Arakaki

Bibliografia

1. GUERRA-GARCIA R. Editorial. Rev Med Hered 1990; 1(1):1.
2. SZKLO M, y NIETO JF. El papel de las revistas de salud pública. Rev San Hig Pub 1993; 67:331-334.

* $\quad$ Editor Asociado 